\title{
Dorsolateral inner preputial graft urethroplasty for anterior urethral strictures: long-term outcomes from a single tertiary care centre
}

\author{
Shantanu Tyagi ${ }^{1} \cdot$ Kalpesh Parmarr $^{1}$ (1) $\cdot$ Anuj Sharma ${ }^{1} \cdot$ Sudheer Devana $^{1} \cdot$ Santosh Kumar ${ }^{1} \cdot$ Shrawan Kumar Singh $^{1}$. \\ Girdhar Bora' ${ }^{1}$. Ravi Mohan Mavuduru'
}

Received: 20 October 2020 / Accepted: 25 January 2021 / Published online: 13 February 2021

(c) The Author(s), under exclusive licence to Springer-Verlag GmbH, DE part of Springer Nature 2021

\begin{abstract}
Purpose Buccal mucosa graft (BMG) is long used as favoured substitute by most reconstructive surgeons for substitution urethroplasty (SU). Though inner preputial skin graft (IPG) was described even earlier than BMG, its usage lately has fallen out of favour. The aim of the study was to evaluate the outcome of a SU with IPG from a tertiary care centre.

Methods A retrospective analysis of prospectively maintained clinical data was conducted at our tertiary care centre enrolling 80 patients with anterior urethral stricture from January 2015 to January 2018. Patients were evaluated for the aetiology, length and site of the urethral stricture. All patients underwent dorsolateral SU with IPG. Post-operative assessment including uroflowmetry and sexual outcomes using IIEF and MSHQ-EJD questionnaires was done at 3 weeks, 3 months, 12 months and half-yearly thereafter. Success was defined by the stable maximum urinary flow value $>14 \mathrm{ml} / \mathrm{s}$ or urethral calibration with 16 French Foley catheter.

Results Mean age of patients was 40 years (18-69). The most common aetiology was post-instrumentation (65\%) and 60\% had stricture at penobulbar site. Mean stricture length was $65 \mathrm{~mm}$. At a mean follow-up of 48 months (range 30-66 months), successful outcomes were seen in 69/80 (87\%). Patients with failure were managed with optical internal urethrotomy (OIU). Uroflowmetry and obstructive symptoms significantly improved and sexual function remained unaffected using IPG for SU. Conclusions Preputial graft is a tissue familiar to the urologist, located very close to the surgical field, easily harvested and operated under regional anaesthesia. Overall success outcomes are acceptable to BMG urethroplasty.
\end{abstract}

Keywords Urethral stricture $\cdot$ Inner preputial skin $\cdot$ Substitution $\cdot$ Long segment $\cdot$ Success

\section{Introduction}

Urethral stricture is a common ailment known to civilisation for around 5000 years [1] and affecting nearly 300 per 100,000 men in recent estimates [2]. Numerous procedures including endoscopic, anastomotic or substitution techniques using flaps or graft have been described for the management of anterior urethral stricture disease [3]. Excision and end to end anastomosis (ETA) is preferred for bulbar urethral stricture with length less than $2 \mathrm{~cm}$, while substitution urethroplasty is the treatment of choice for strictures of longer length [4]. The grafts for urethral substitution can be harvested from the locally available preputial skin, the distal

Kalpesh Parmar

kalpesh010385@gmail.com

1 Department of Urology, Post Graduate Institute of Medical Education and Research, Chandigarh, India penile skin, inguinal skin and scrotal skin or from remote epithelial sites like buccal, lingual, bladder and colonic mucosa or from tissue engineered scaffolds [3]. A standard graft material for urethral substitution should be resilient towards urinary environment, be readily available, hair-free, conducive for neovascularization and impart minimal morbidity to graft site [4]. Buccal mucosa and preputial skin are commonly used donor sites for grafts used in urethral substitution in present practice. Inner preputial skin graft (IPG) has the advantage of being in use for a longer time, available locally, can be harvested under same regional anaesthesia of urethroplasty and morbidity of general anaesthesia can be avoided in high-risk patients. In the context of ongoing COVID-19 pandemic, it has added safety as the surgical field lies away from sites of aerosol production unlike BMG. In spite of the above-mentioned merits, there has been a trend towards increased use of BMG over the last few decades given its described optimal characteristics [5] and reportedly 
better success rates[6], but level-1 evidence for the same is long awaited [7]. This could partly be attributed to paucity of well-designed studies reporting outcomes of preputial graft urethroplasty. Through this study, we intend to evaluate the long-term outcomes of substitution urethroplasty with inner preputial graft from our tertiary care centre.

\section{Materials and methods}

This is a single tertiary care centre study involving retrospective analysis of a prospectively maintained database. Institute ethics committee clearance was taken (NK/6242/ Study/41). From January 2015 to January 2018, patients presenting to out-patient department of our institution with the diagnosis of anterior urethral stricture were enrolled in this study. Inclusion criteria were strictures $>2 \mathrm{~cm}$ involving bulbar urethra, $>1 \mathrm{~cm}$ involving penile urethra, patients requiring repeated internal urethrotomy or dilatations. Patients with unavailable or unhealthy or unsuitable preputial skin (lichen sclerosis) were excluded. Records of these patients were maintained and analysed prospectively. Pre-operative assessment included: calibration of the urethra, uroflowmetry (UFM), retrograde urethrography (RGU), micturating cystourethrography (MCU), International Prostate Symptom Score (IPSS) [8] for lower urinary tract symptoms (LUTS), International Index of Erectile Function (IIEF) Score, [8] and Male Sexual Health Questionnaire for Ejaculatory Dysfunction (MSHQ-EJD)[9].

The procedure was started with on-table ureteroscopic assessment of urethral calibre, length of strictured segment and appearance of urethral mucosa along with synechia or sinuses. The strictured urethral length was laid open over guidewire or 4 Fr ureteric catheter and the length of the strictured segment measured. The graft harvest site was cleaned with betadine saline. A circumcoronal incision was marked over inner preputial skin after retracting the prepuce. The breath of the preputial incision was adjusted according the length of graft required. In case of lengthier defect, a wider graft was harvested so that it can be divided longitudinally into two grafts of equal length. Unlike BMG harvest, IPG harvest does not require lignocaine and adrenaline injection at bed site. The epithelium was incised and gentle dissection was contemplated and the plane was created above dartos muscle. Light traction with stay sutures at two ends helps in maintaining the plane and harvesting of even thickness graft. It is crucial to be in the right plane between skin and dartos muscle. Deeper dissection can lead to thick grafts and unwanted bleeding from venous plexus. The graft harvested in this fashion is much alike mucosal graft in spite having a skin origin and needs minimal bench preparation. In case of small segment strictures, only a part of inner preputial skin may be harvested. Back table preparation included meticulous removal of any excess subepithelial tissue or dartos muscle fibres. Index finger support act as a base as well and avoids excessive thinning of the graft. The donorsite edges are approximated with interrupted absorbable sutures. After harvesting, the IPG was placed to bridge gap over the opened strictured segment in "Dorsolateral fashion" similar to Kulkarni's technique [10]. In this way the opened strictured segment was completely roofed by IPG over a 16 French Foley catheter. Incision was closed in layers at completion without any drain placement (Fig. 1). Peri-catheter RGU was done in all cases at 3 weeks prior to catheter removal. If any leak was documented, Foley catheter was retained for one more week and only removed after the documentation of "no-leak" on imaging (Supplementary video).

Primary outcome was the success rate and secondary outcome was patient related outcome measures (PROMs) after IPG substitution urethroplasty. All patients underwent postoperative assessment and follow-up was done at 3 weeks, 3 months, 12 months and half yearly thereafter. Uroflowmetry (UFM) was done on every post-operative visit and subsequent calibration or cystourethroscopy was done if UFM was abnormal $(\leq 14 \mathrm{ml} / \mathrm{s})$. Success was defined by the stable maximum urinary flow value $>14 \mathrm{ml} / \mathrm{s}$ or urethral calibration with 16 French Foley catheter. Need of any secondary intervention, including dilatation was counted as failure.

The "statistical analysis" was done using Statistical Package for Social Sciences "SPSS Inc., Chicago, IL, version 23.0 for Windows". Proportions were judged using 'Chisquare or Fisher's exact test' and t test was used for matching means between study groups. Each statistics were executed at a "significance level of $\alpha \leq 0.05$ ".

\section{Results}

A total of 80 patients of anterior urethral stricture were operated with IPG substitution urethroplasty between January 2015 and January 2018 at our centre. The mean age at presentation was 40 years (18-69). The mean stricture length was $65 \mathrm{~mm}(30-100)$. The mean duration of LUTS at presentation was $29 \pm 7$ months and most common aetiology was catheter-induced stricutres (65\%). Up to $51 \%$ of patients had undergone bougie dilatation prior to presentation at our centre. The most common site of narrowing was penobulbar junction $(60 \%)$ among the entire cohort. All the patients were operated under regional anaesthesia. Based on the length of the stricture, either partial or complete circumferential graft harvest was done. Longitudinal division of harvested graft used in end to end fashion to bridge longer gaps was done in four patients. The mean operative duration was 160 min and mean hospital stay was 3.5 days. At a median follow-up was 48 months (30-66 months), $69 / 80(87 \%)$ patients were documented to have successful 

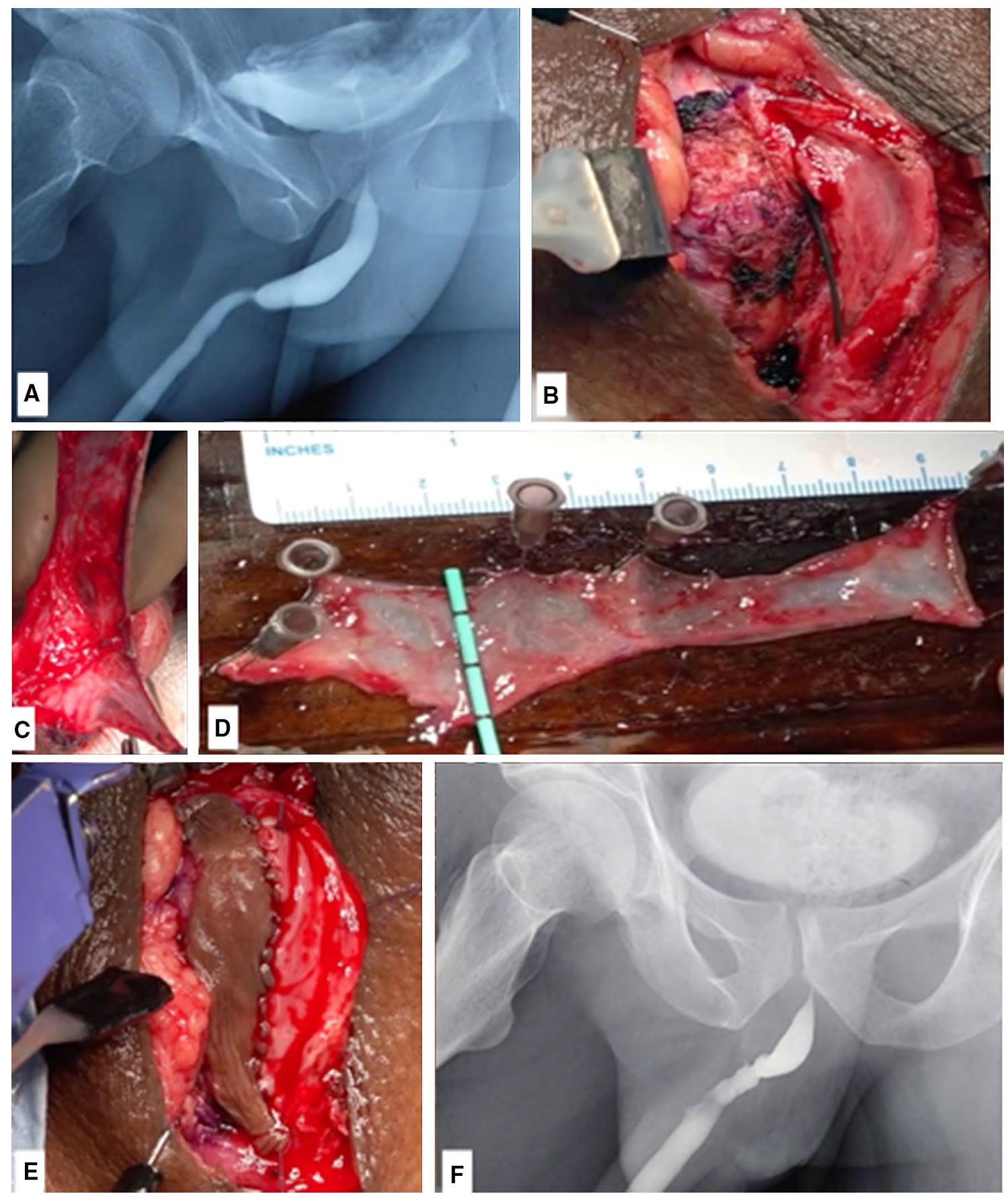

Fig. 1 a Retrograde urethrogram (RGU) in a 26-year male showing long segment penobulbar stricture. b Intra-operative image showing urethral mobilization at stricture site with lay opening of urethra over guide wire. c Inner preputial skin graft harvest. d Spread fixation of

outcomes (Table 1). Seventy-five percent (7/11) of the failures were seen within 24 months after SU with IPG. All failures had anastomotic site strictures which were managed by endoscopic optical urethrotomy. In patients with partial graft harvest, five patients had preputial oedema at the donor site in the post-operative period. Preputial edema resolved preputial graft on wooden plank. e Dorsolateral fixation of preputial graft over corpora cavernosa and suturing one end of graft to urethral margin. f Follow-up RGU of the same patient showing well-distended strictured segment with mild irregular outline

with conservative measures in three patients, but two required circumcision for non-resolving preputial oedema. Wound infection was seen in three patients which was successfully managed conservatively. No patient had more than grade IIIa Clavien-Dindo complication in the postoperative period. Urine flow and IPSS were significantly 
Table 1 Baseline pre-operative, intra-operative and post-operative characteristics of study population

\begin{tabular}{|c|c|}
\hline & IPG $(n=80)$ \\
\hline \multicolumn{2}{|l|}{ Baseline variables } \\
\hline Age (Years) & $40.23 \pm 13.16$ \\
\hline $\operatorname{BMI}\left(\mathrm{Kg} / \mathrm{m}^{2}\right)^{*}$ & $26.88 \pm 5.41$ \\
\hline Duration (months)* & $29.27 \pm 7.34$ \\
\hline Length of stricture $(\mathrm{mm})^{*}$ & $65.9 \pm 4.11$ \\
\hline \multicolumn{2}{|l|}{ Comparative site of stricture } \\
\hline Pendular & $13(16 \%)$ \\
\hline Bulbar & $17(21.5 \%)$ \\
\hline Penobulbar & $48(60 \%)$ \\
\hline Pan-anterior & $2(2.5 \%)$ \\
\hline \multicolumn{2}{|l|}{ Aetiology } \\
\hline Post-instrumentation & $52(65 \%)$ \\
\hline Post-inflammatory & $20(25 \%)$ \\
\hline Idiopathic & $8(10 \%)$ \\
\hline \multicolumn{2}{|l|}{ Pre-operative interventions } \\
\hline Dilatation & $41(51 \%)$ \\
\hline OIU & $14(17.5 \%)$ \\
\hline Urethroplasty & $2(2.5 \%)$ \\
\hline None & $23(29 \%)$ \\
\hline \multicolumn{2}{|l|}{ Intra-operative variables } \\
\hline Graft placement site & Dorsolateral onlay \\
\hline Operative time (minutes)* & $159.83 \pm 15.56$ \\
\hline \multicolumn{2}{|l|}{ Post-operative variables } \\
\hline Hospital stay after surgery (days)* & $3.5 \pm 1.17$ \\
\hline Follow-up duration (median) [Range] & $48(30-66)$ \\
\hline Success rate & $69 / 80(87 \%)$ \\
\hline
\end{tabular}

$*$ Mean \pm SD

improved and maintained after successful SU with IPG. The Q max showed marked improvement of $16 \mathrm{ml} / \mathrm{s}$ over the pre-operative values. The immediate improvement in IPSS score was even maintained on long-term follow-up. PROMs assessment in terms of IIEF and MSHQ-EJD questionere showed no significant difference in the post-operative period after IPG urethroplasty (Table 2).

\section{Discussion}

Urethral stricture is a frequent and challenging disease in the field of urology. Inspite of the variety of procedures available to treat it at present, there is no one approach which is superior over another [11]. In contrast to developed countries, instrumentation is the major cause of anterior urethral stricture disease in developing countries like India. In our study as well, most common cause of urethral stricture was history of urethral catheterization [12]. Although the location of stricture is determined by the aetiology, commonest location overall reported in literature is penobulbar junction as a result of abundant peri urethral glands. Length of the urethral stricture plays most crucial role in management; however, additional factors such as aetiology, location, degree of spongiofibrosis and previous treatment also plays decisive role. For long segment anterior urethral strictures where excision and end to end anastomosis is not feasible, substitution urethroplasty is treatment of choice [13].

There are glut of tissues that can be used as substitute such as grafts or flaps; however, commonly preferred graft by most reconstructive urologist in the past 2 decades is Buccal mucosa. Its widespread application is partly due to its favourable characteristics, thick epithelium, highly vascularised lamina propria and resistance to infection. Inner preputial skin graft is second most commonly used graft which has gone out of favour in the recent past. Numerous studies have reported the outcomes of SU with BMG [14, 15]. While majority of comparative studies report better outcomes with BMG as compared to IPG, $[16,17]$ few studies have also reported similar outcomes between the two $[8,18]$. Furthermore, Lumen et al.[19] in their comparative study

Table 2 Functional outcomes at a median follow-up of 48 months

\begin{tabular}{|c|c|c|c|c|c|c|c|}
\hline \multirow[t]{2}{*}{ Pre-operative } & \multicolumn{5}{|l|}{ Follow-up } & \multirow[t]{2}{*}{$p$ value* } & \multirow{2}{*}{$\begin{array}{l}\text { Change from pre- } \\
\text { operative values }\end{array}$} \\
\hline & $\begin{array}{l}\text { At } 3 \mathrm{~m} \\
(n=80)\end{array}$ & $\begin{array}{l}\text { At } 12 \mathrm{~m} \\
(n=80)\end{array}$ & $\begin{array}{l}\text { At } 24 \mathrm{~m} \\
(n=80)\end{array}$ & $\begin{array}{l}\text { At } 36 \mathrm{~m} \\
(n=75)\end{array}$ & $\begin{array}{l}\text { At } 48 \mathrm{~m} \\
(n=65)\end{array}$ & & \\
\hline \multicolumn{8}{|c|}{$\mathrm{Qmax}(\mathrm{ml} / \mathrm{s})($ Mean $\pm \mathrm{SD})$} \\
\hline $6.99 \pm 1.78$ & $25.15 \pm 4.52$ & $24.14 \pm 3.40$ & $23.92 \pm 5.00$ & $23.51 \pm 4.23$ & $22.52 \pm 3.57$ & $<0.001$ & $16.32 \pm 4.11$ \\
\hline \multicolumn{8}{|c|}{ IPSS (Mean \pm SD) } \\
\hline $16.24 \pm 3.35$ & $3.53 \pm 1.57$ & $3.64 \pm 1.91$ & $3.46 \pm 1.83$ & $3.61 \pm 1.29$ & $3.56 \pm 1.33$ & $<0.001$ & $12.35 \pm 2.34$ \\
\hline \multicolumn{8}{|c|}{ IIEF $($ Mean \pm SD) } \\
\hline $25.98 \pm 6.14$ & $25.61 \pm 7.32$ & $26.41 \pm 6.39$ & $25.79 \pm 4.63$ & $26.13 \pm 5.56$ & $25.14 \pm 6.12$ & 0.71 & $0.64 \pm 0.11$ \\
\hline \multicolumn{8}{|c|}{ MSHQ-EJD $($ Mean \pm SD) } \\
\hline $13.21 \pm 5.76$ & $13.67 \pm 5.91$ & $14.10 \pm 5.12$ & $14.24 \pm 4.73$ & $14.53 \pm 4.40$ & $14.24 \pm 5.04$ & 0.44 & $0.75 \pm 0.12$ \\
\hline
\end{tabular}

*Compared to pre-operative values 
reported better outcomes with IPG. Donor-site complication is an important aspect when considering outcomes of substitution urethroplasty. BMG harvest is associated with bleeding, swelling, oral numbness and bothersome pain in the early post-operative period [20]. The intake of normal diet is delayed following BMG harvest and patients require additional care for oral hygiene and rehabilitation for food intake. In comparison, inner preputial skin is familiar to all urologist, available in same operative field, avoids general anaesthesia for graft harvest and complications are minimal [21].

However, none of the comparative studies have randomised methodology; therefore, superiority of one over the other remains debated (Table S1). Similarly, the evidence for outcomes after SU with IPG awaits well-designed studies reporting long-term outcomes with large sample size. Bapat et al. [22] reported $86 \%$ success rate after IPG in their retrospective study of 73 patients with a mean followup of 14 months. In the light of previous studies, which have reported that success rates after SU declines with time especially during the first $2-5$ years in the post-operative period [16], longer follow-up is a pre-requisite. At a mean follow-up of nearly 50 months, Radopoulos et al. [23] have reported $71 \%$ success rate in their study of 21 patients. Compared to these studies, our prospective study enrolling 80 patients, reported $87 \%$ success rate at a median follow-up of 48 months. Future, randomised studies may establish the best graft material for SU in terms of successful outcomes [24].

Along with success rate, treatment-related adverse events must also be given due weightage when contemplating graft material for SU. Donor-site morbidity of BMG has been reported to affect immediate post-operative course and rehabilitation [25]. On the other hand, preputial oedema at IPG donor site as reported in our study can be avoided by doing a complete circumcision at the time of harvest. Preputial oedema may resolve on its own in long term as was seen in three of our patients. However, two patients required circumcision at follow-up of 3 months for non-resolving preputial oedema and cosmetic concern.

Patient-reported outcomes measures (PROMS) are as equally important as objective variables when assessing success after SU [21]. Therefore, we have included PROMS like IIEF and MSHQ to facilitate complete evaluation of outcomes after SU. The functional outcomes were unaffected following surgery and during long-term follow-up.

The limitations of our study are non-randomised design. A multinational/multi-institutional study population enrolling larger sample size is definitely needed to confirm our findings, which could be universally applicable and reproducible. Further, a well-designed randomised controlled trial comparing IPG versus BMG is needed to report the superiority of one over the other. As regards to the highlights of our study, we report the long-term follow-up of patients undergoing substitution urethroplasty using inner preputial skin for anterior urethral strictures. Both the anatomic and functional outcomes were measured in all the patients.

\section{Conclusion}

Till the time, we are awaiting level-1 evidence on best graft material. Situations where SU with BMG is not appropriate or available like oral leucoplakia, poor oral hygiene with heavy tobacco smoking/chewing, previous irradiation, previous BMG), IPG remains a feasible alternative. These two techniques of SU, should be considered as "complementary" to each other and, therefore, the technique of IPG harvest and its use in genitourinary reconstruction should remain part of contemporary urology practice.

Supplementary Information The online version contains supplementary material available at https://doi.org/10.1007/s00345-021-03613-9.

Author contributions KP and ST - concepts, design, definition of intellectual content, literature search, clinical studies, experimental studies, and data acquisition. AS, SD, and GB-data analysis, statistical analysis, manuscript preparation. SKS, RM, and SK-manuscript editing and manuscript review.

Funding None.

Data availability On request.

\section{Compliance with ethical standards}

Conflict of interest The authors declare that they have no conflict of interest.

Ethical approval NK/6242/Study/41.

Consent to participate Taken.

\section{References}

1. Das S (2007) Urology in ancient India. Indian J Urol 23(1):2

2. Stein DM, Thum DJ, Barbagli G et al (2013) A geographic analysis of male urethral stricture aetiology and location. BJU Int 112:830-834

3. Mangera A, Chapple C (2010) Management of anterior urethral stricture: an evidence-based approach. Curr Opin Urol 20:453-458

4. Levy ME, Elliott SP (2017) Graft use in bulbar urethroplasty. Urol Clin North Am 44:39-47

5. Markiewicz MR, Margarone JE 3rd, Barbagli G, Scannapieco FA (2007) Oral mucosa harvest: an overview of anatomic and biologic consideration. Eur Assoc Urol 5:179-187 
6. Barbagli G (2007) Interview with Dr Guido Barbagli. Substitution urethroplasty: Which tissues and techniques are optimal for urethral replacement? Eur Urol 52:602-604

7. Sharma G, Sharma S, Parmar K (2020) Buccal mucosa or penile skin for substitution urethroplasty: a systematic review and metaanalysis. Indian J Urol 36:81-88

8. Raber M, Naspro R, Scapaticci E et al (2005) Dorsal onlay graft urethroplasty using penile skin or buccal mucosa for repair of bulbar urethral stricture: results of a prospective single center study. Eur Urol 48(6):1013-1017

9. Bertrand LA, Voelzke BB, Elliott SP et al (2016) Measuring and predicting patient dissatisfaction after anterior urethroplasty using patient reported outcomes measures. J Urol 196(2):453-461

10. Kulkarni S, Barbagli G, Sansalone S, Lazzeri M (2009) One-sided anterior urethroplasty: a new dorsal onlay graft technique. BJU Int 104(8):1150-1155

11. Andrich DE, Mundy AR (2008) What is the best technique for urethroplasty? Eur Urol 54:1031-1041

12. Fenton AS, Morey AF, Aviles R et al (2005) Anterior urethral strictures: etiology and characteristics. Urology 65:1055-1058

13. Barbagli G, Palminteri E, Balo S, Picinoti A, Lazzeri M (2002) Dorsal onlay graft urethroplasty. Contemp Urol 14:18-32

14. Kane CJ, Tarman GJ, Summerton DJ, Buchmann CE, Ward JF, O'Reilly KJ et al (2002) Multi-institutional experience with buccal mucosa onlay urethroplasty for bulbar urethral reconstruction. J Urol 167:1314-1317

15. Pansadoro V, Emiliozzi P, Gaffi M, Scarpone P (1999) Buccal mucosa urethroplasty for the treatment of bulbar urethral strictures. J Urol 161:1501-1503

16. Barbagli G, Kulkarni SB, Fossati N et al (2014) Long-term follow up and deterioration rate of anterior substitution urethroplasty. $\mathrm{J}$ Urol 192:808-813

17. Berger AP, Deibl M, Bartsch G et al (2005) A comparison of onestage procedures for post- traumatic urethral stricture repair. BJU Int 95:1299-1302
18. Hussein MM, Almogazy H, Mamdouh A, Farag F, Rashed E, Gamal W et al (2016) Urethroplasty for treatment of long anterior urethral stricture: Buccal mucosa graft versus penile skin graftdoes the stricture length matter? Int Urol Nephrol 48:1831-1835

19. Lumen N, Browaeys H, Hoebeke P, Ooster-linck W (2008) Ventral onlay graft urethroplasty using genital skin or buccal mucosa in the treatment of bulbar strictures: a retrospective analysis of 41 cases. Curr Urol 2:10-15

20. Andrich DE, Mundy AR (2001) Substitution urethroplasty with buccal mucosal-free grafts. J Urol 165:1131-1134

21. Erickson BA, Ghareeb GM (2017) Definition of successful treatment and optimal follow-up after urethral reconstruction for urethral stricture disease. Urol Clin North Am 44:1-9

22. Bapat SS, Padhye AS, Yadav PB, Bhave AA (2007) Preputial skin free graft as dorsal onlay urethroplasty: our experience of 73 patients. Indian J Urol 23(4):366-368

23. Radopoulos D, Tzakas C, Dimitriadis G, Vakalopoulos I, Ioannidis S, Vasilakakis I (2007) Dorsal on-lay preputial graft urethroplasty for anterior urethra strictures repair. Int Urol Nephrol 39(2):497-503

24. Parmar K, Tyagi S, Singh SK, Kumar S, Mete U, Mohan R et al (2019) Comparative analysis of successful outcome after substitution urethroplasty with "Buccal Mucosa Graft versus Inner Preputial Skin Graft" for anterior urethral stricture disease. Eur Urol Suppl 18(1):e524

25. Akyüz M, Güneş M, Koca O et al (2014) Evaluation of intraoral complications of buccal mucosa graft in augmentation urethroplasty. Turk J Urol 40(3):156-160

Publisher's Note Springer Nature remains neutral with regard to jurisdictional claims in published maps and institutional affiliations. 